\title{
Selection of AU-rich transiently expressed sequences: Reversal of cDNA abundance
}

\author{
KHALID S.A. KHABAR, ${ }^{1}$ MOHAMMED DHALLA, ${ }^{1}$ LATIFA AL-HAJ, ${ }^{1}$ TALA BAKHEET, ${ }^{2}$ CHEIKH SY, and \\ MOHAMMED NAEMMUDDIN ${ }^{\mathbf{1}}$ \\ ${ }^{1}$ Interferon and Cytokine Research Unit, Department of Biological and Medical Research, Bioinformatics Section, King Faisal Specialist \\ Hospital and Research Center, Riyadh 11211, Saudi Arabia \\ ${ }^{2}$ Department of Biostatistics, Epidemiology, and Scientific Computing, King Faisal Specialist Hospital and Research Center, Riyadh 11211, \\ Saudi Arabia
}

\begin{abstract}
Study of early and transient response gene expression is important for understanding the mechanisms of response to growth stimuli and exogenous agents such as microbes, stress, and radiation. Many of the cytokines, proto-oncogenes, and other transiently expressed gene products are encoded by mRNAs that contain AU-rich elements (AREs) in their $3^{\prime}$ untranslated regions (UTRs). In this article, we describe an approach to selectively synthesize ARE-containing cDNA (ARE-cDNA) using an innovative combination of culture treatment, thermostabilization of reverse transcriptase (RT) by the disaccharide trehalose, and use of optimized ARE-specific oligomers. The monocytic cell line, THP-1, was treated with cycloheximide and endotoxin to enrich for ARE-mediated gene expression followed by the RT procedure. Selection of ARE-cDNA with simultaneous suppression of abundant CDNA was made possible using the procedure as monitored by the preferential expression of IL-8, an ARE-cDNA molecule, over the abundant housekeeping cDNA, $\beta$-actin. The use of trehalose dramatically reversed cDNA abundance, resulting in almost complete suppression of housekeeping cDNA. Finally, construction of specialized ARE-cDNA libraries confirmed the selectivity of ARE-cDNAs and the presence of rare genes. The ability to reverse the abundance of housekeeping and other highly expressed genes toward ARE genes facilitates the discovery and study of rare early response and transiently expressed genes.
\end{abstract}

Keywords: AU-rich elements; transient transcripts; cytokines; reverse transcriptase; mRNA abundance; cycloheximide; trehalose

\section{INTRODUCTION}

Many of the cDNA libraries and gene discovery/expression tools such as differential display, differential screening of the cDNA library, expressed sequence tags sequencing (EST), and cDNA microarrays are biased toward a certain threshold of mRNA abundance (Duggan et al. 1999). Thus, rare and transiently expressed mRNAs/cDNAs that contain $\mathrm{AU}(\mathrm{T})$-rich elements (AREs) are underrepresented and can be easily missed in cDNA libraries and subsequently in expression data of cDNA microarrays. AREs are found in the 3' UTRs of many growth factor and proto-oncogene mRNAs (Shaw and Kamen 1986; Chen and Shyu 1995) and are thought to act as determinants of mRNA instability (Shaw

Reprint requests to: Khalid S.A. Khabar, Department of Biological and Medical Research, Interferon and Cytokine Research Unit, P.O. Box 3354, MBC-03, Riyadh 11211, Saudi Arabia; e-mail: khabar@kfshrc.edu.sa; fax: 966-1-442-7858.

Article and publication are at http://www.rnajournal.org/cgi/doi/ 10.1261/rna.5121704. and Kamen 1986). We showed that the ARE-gene family is larger than what was previously thought and encodes many early and transient response genes belonging to a variety of biological processes (Bakheet et al. 2001, 2003). In this article, we describe an approach for enrichment of the expressed ARE-gene family. This procedure resulted not only in synthesis of known ARE-cDNAs that were otherwise masked by overexpressed genes in many traditional techniques, but also resulted in synthesis of rarely expressed genes and suppression of the abundant cDNAs such as $\beta$-actin. The discovery and study of the expression of AREmodulated genes in inflammation and cancer can be greatly facilitated by selection and uncovering of ARE genes.

\section{RESULTS AND DISCUSSION}

\section{Cellular model and primer design}

The monocytic leukemia cell line THP-1 was used as a cellular study model; it is a tumor cell line that corresponds 
to immature monocytic cells, and is rich in both constitutive and inducible ARE-mRNAs such as interleukin-8 (IL-8) and tumor necrosis factor (TNF- $\alpha$; Murayama et al. 1997; Al-Humidan et al. 1998; Frevel et al. 2003). We first treated the cell line with lipopolysaccharide (LPS), a potent inducer of cytokine (Al-Humidan et al. 1998; Frevel et al. 2003) and cyclohexmide (CHX). CHX blocks protein synthesis and drives the expression of primary response genes that does not require prior protein synthesis (Reeves and Magnuson 1990). Also, it is known that CHX increases AU-rich mRNA stability (Shaw and Kamen 1986). We used the first-strand cDNA synthesis step to select for ARE-cDNAs.

Selectivity toward ARE-cDNA was approached by utilizing two degenerate universal $3^{\prime}$ primers that were specifically targeted to ARE consensuses (Chen and Shyu 1995; Zubiaga et al. 1995). These ARE consensuses are Class I AREs that have discontinuous nonamers, UUAUUUAWW, class II AREs having at least two overlapping copies of the nonamer (Chen and Shyu 1995), and the bioinformaticsderived consensus 13-bp ARE, WWWUAUUUAUWWW (Bakheet et al. 2001). Both of the oligoprimers consist of 13 nt that comprise two and three copies of pentamer motif sequences (AUUUA) and have been designated AT-P and TA-P, respectively (Table 1 ). In principle, these primers contain both Class I and Class II AREs (Chen and Shyu 1995) and contain the bioinformatics-derived ARE consensus (Bakheet et al. 2001), and remain to be empirically validated. The AT-P oligomer contains a 3-base anchor ( $\mathrm{V}=\mathrm{A}, \mathrm{C}$, or $\mathrm{G}$ ) at the $3^{\prime}$ end, similar to the design concept of the oligodT anchored primers. The TA-P oligomer contains mismatchs $(\mathrm{W}=\mathrm{A}$ or $\mathrm{T}$ and $\mathrm{V}$ ) in the middle pentamer to allow further recovery of AREs with small deviations from ARE consensuses. Two additional primers were designed that, in addition to their AREs, included in the $5^{\prime}$ ends sequences such as the Xho site, CTCGAG.
To monitor the preferential enrichment of ARE-cDNAs, we used the ARE-cDNA, IL-8, and the non-ARE cDNA, $\beta$-actin, as controls. IL- 8 mRNA contains discontinuous multiple nonamers VWAUUUAUU in a AU-rich flanking region with two overlapping penameric repeats, and thus conforms to Class II AREs (Table 1). $\beta$-actin is a housekeeping gene that is abundantly expressed in a variety of cell lines and has the pentamer (AUUUA) in a non-ARE flanking region, UCAGG(AUUUA)AAAA, and thus acts as a stringent control for selecting ARE-mRNAs (Table 1).

\section{Enrichment of ARE-cDNAs}

We first employed the regular Moloney murine leukemia virus reverse transcriptase (MMLV RT); this RT reaction did successfully lead to preferential synthesis of the typical ARE-cDNA (IL-8) when compared to the non-ARE $\beta$-actin cDNA (data not shown). We then used SuperScript II RT (RNAse $\mathrm{H}$ negative mutant), which functions at a higher temperature than the regular MMLV. Increasing the RT temperature from $42.5^{\circ} \mathrm{C}$ (Fig. 1A, upper panel, lanes 1,3 ) to $52^{\circ} \mathrm{C}$ (Fig. 1A, upper panel, lanes 2,4 ) resulted in significant reduction in the abundance of the $\beta$-actin cDNA without significantly affecting IL-8 abundance. It is unlikely that this decrease was due to cDNA elongation deficiency because both cDNAs are of comparable size $(1.7-1.8 \mathrm{~kb})$. Increasing the concentration of the primer from $15 \mu \mathrm{g} / \mathrm{mL}$ (Fig. 1A, upper panel, lanes 1,2 ) to $25 \mu \mathrm{g} / \mathrm{mL}$, that is, $6 \mu \mathrm{M}$ (Fig. 1A, upper panel, lanes 3,4) further attenuated the abundance of $\beta$-actin cDNA without significantly affecting IL-8 cDNA signal. For comparison, the regular pattern of abundance of IL- 8 and $\beta$-actin CDNA in THP- 1 and other cell lines was shown in Figure 1B. The use of the TA-P primer, which has another variation of the ARE sequence, was also demonstrated (Fig. 1A, lower panel). Both increas-

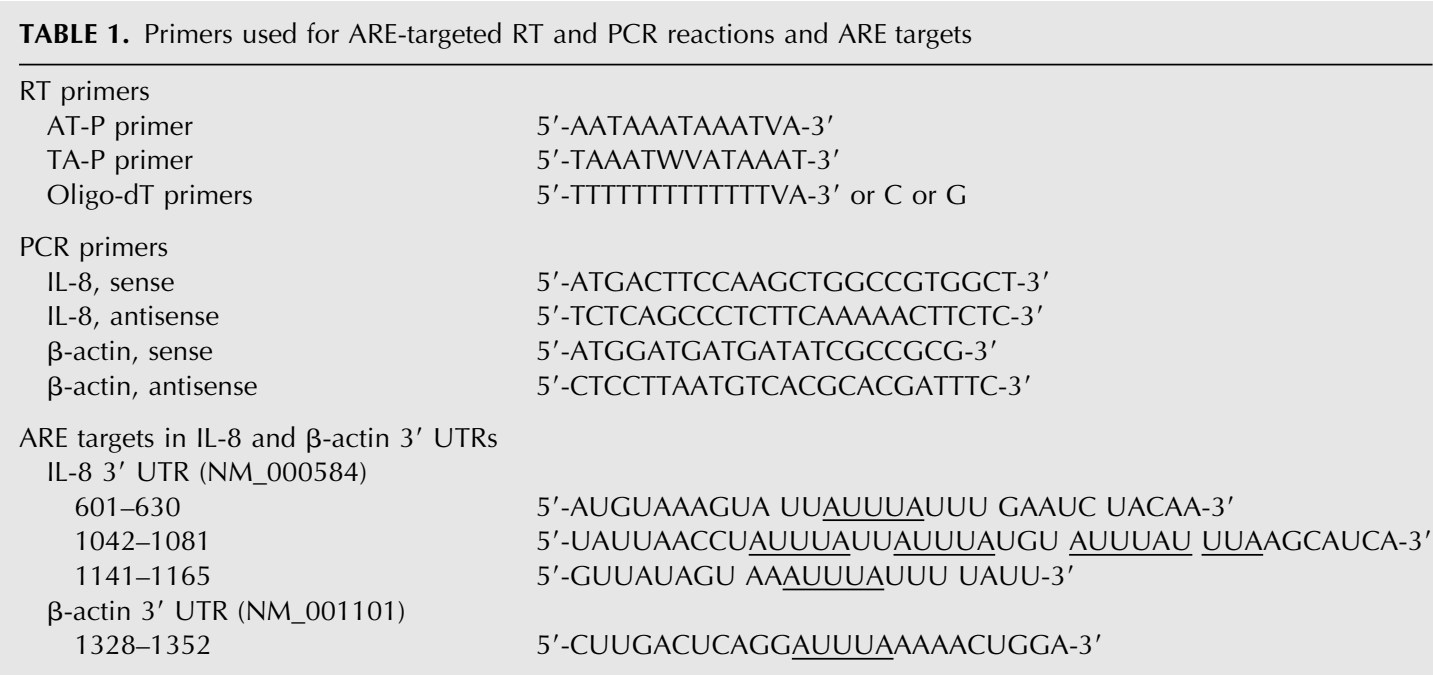

Numbers indicate nucleotide sequence according to the indicated RefSeq record. 
A

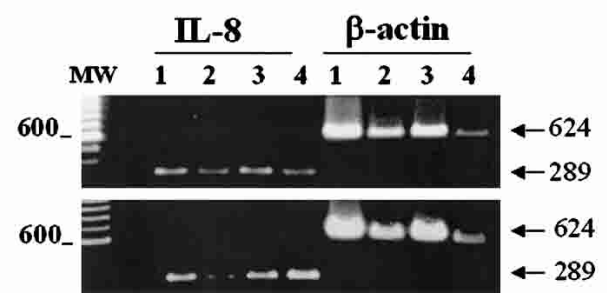

B

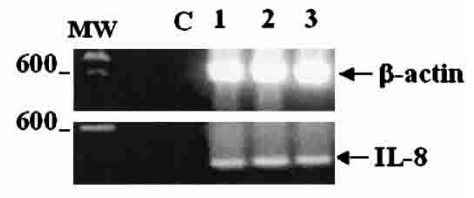

\section{Construction of ARE-cDNA libraries and cDNA abundance features}

To verify the enrichment of ARE-mRNAs and to understand the repertoire of the ARE-transcriptome, we constructed a mini-ARE-cDNA library using the described approach. Thus, the purpose of the mini library, which was without size selection and with a moderate number of clones, was not generation of the full-length cDNAs. Sequencing of the expressed sequences derived from the ARE-cDNA mini library and a control oligo-dT primed cDNA mini library was performed. Table 2 shows the characteristics of these sequences in the AREcDNA mini library and the control library. As a control, the cDNAs were BLASTed against the human genome and we found that almost all $(\sim 96 \%)$ of

ing temperature and primer concentration attenuated the $\beta$-actin cDNA signal without affecting the IL- 8 cDNA signal (Fig. 1A, lower panel). The use of TA-P primer when compared to the AT-P primer resulted in marginal enrichment in respect to the ARE-rich IL-8 cDNA (Fig. 1A, lower panel, lane 4) apparently due to the sequence variation of AREspecific primers.

For further refinement for suppression of $\beta$-actin cDNA abundance while maintaining selection of ARE CDNA, we included trehalose in the RT reaction. Trehalose is a disaccharide that has been shown to stabilize several enzymes, including RT, at temperatures as high as $60^{\circ} \mathrm{C}$ (Mizuno et al. 1999). This property allowed us to use a high annealing temperature in the RT reaction. As shown in Figure 2, the inclusion of trehalose, and thus, a higher annealing temperature, resulted in dramatic suppression of abundant cDNA without affecting the less abundant IL-8 cDNA signal. The use of lower amounts of input RNA contributed to the almost complete suppression of $\beta$-actin cDNA (Fig. 2, lane 5).

Thus, in addition to biological selection of ARE-mRNAs with CHX treatment and utility of ARE-specific RT primer, the use of high temperatures and high primer concentration in the RT reaction was necessary for optimum selectivity. The higher temperatures achieved due to the use of trehalose not only allow increased specificity but probably reduced secondary structure of mRNA (Yamada et al. 1998). The higher primer concentration may compensate for the lower hydrogen-bonding energy between the AT-rich primer and mRNA AU-rich regions. In general, the different ARE primers, AT-P, TA-P, and two additional primers that had anchored the $5^{\prime}$ sequence containing restriction sites (data not shown), had only marginal differences among themselves in terms of preferential synthesis of IL-8 cDNA over $\beta$-actin cDNA. the cDNAs matched (minimum identity, 90\%) the entire human genome, indicating that our libraries are largely free from vector and bacterial sequences that are commonly encountered in cDNA libraries. We found only four vectoronly sequences $(\sim 1 \%)$ in our libraries and these were removed from further analysis. The cDNAs from both libraries were compared against two databases, the human expressed sequence tags (dbEST) database and GenBank (using records annotated as mRNAs; Table 2). Almost onethird of the ARE-cDNA sequences had no matches to expressed transcripts, that is, either ESTs or mRNAs. In contrast, most of the oligo-dT-derived cDNA sequences had significant matches to either dbEST or mRNAs in GenBank records.

An important functional aspect of the ARE-cDNA library is that there was a significant reversal of abundance; the abundant housekeeping ribosomal proteins were dramatically reduced, from $29 \%$ in the oligo-dT control cDNA library to $4 \%$ in the ARE-cDNA library as measured by the redundancy of sequences in both libraries.

\section{Sequence and functional characteristics of ARE-cDNAs}

Assessment of ARE-mRNA enrichment was achieved by assessment of the redundancy of known sequences that harbored, in their 3' UTRs, the minimum ARE motif, WWWU(ATTTA)UWWW, with a mismatch of $1 \mathrm{nt}$ in the region flanking the conserved pentamer, using our AREmRNA database (ARED 2.0; Bakheet et al. 2003) and a recent (unpublished) update based on the latest RefSeq release (April 2003). Enrichment of ARE-mRNAs was significant in the ARE-cDNA library-47\% were cDNAs with homology to known ARE-cDNAs-when compared to the 


\section{$\underline{\text { IL8 }} \quad$ B-actin}

\section{MW 123345122345}

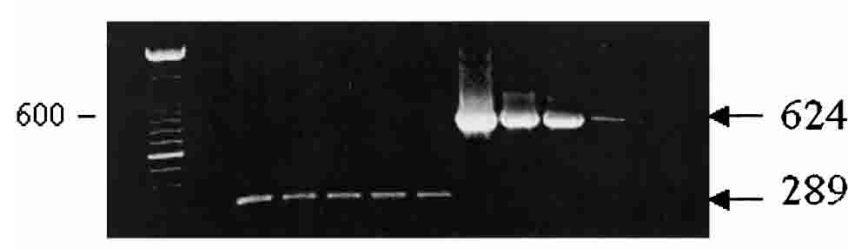

\section{Trehalose ---++---++}

FIGURE 2. Effect of trehalose on the efficiency of specific ARE priming and reversal of abundant cDNA. Total RNA samples (lanes 1,2,4, $0.5 \mu \mathrm{g}$; lanes $3,5,0.25 \mu \mathrm{g}$ ) were extracted from THP-1 cells that were treated with CHX and LPS. cDNA was synthesized using SuperScript II with TA-P primer (Table 1) at a concentration of $25 \mu \mathrm{g} / \mathrm{mL}$. RT was performed in the absence (lanes 1,2,3) or presence of trehalose (lanes $4,5)$ at a priming annealing temperature of $60^{\circ} \mathrm{C}$. Specific PCRs for IL-8 and $\beta$-actin were performed using standard PCR conditions. Lane 1 shows the regular abundance of $\beta$-actin and IL- 8 at the same PCR conditions used. Upper bands are of the expected size of the $\beta$-actin product and the lower bands represent IL- 8 cDNA of the expected size. Lack of DNA contamination was verified by the absence of larger specific amplified products. Each RNA sample was subject to control for DNA contamination in which PCR was performed with mRNA but no cDNA.

control library (27\%; Table 2). For example, the most abundant ARE-mRNA was IL-8, representing approximately 3\% of the ARE-cDNA mini library. IL-8 is a proinflammatory chemokine and typical ARE-mRNA, that is, with Class II AREs (Table 1); the role of the AREs in the IL-8 3' UTR has been functionally validated in the turnover of IL- 8 mRNA (Winzen et al. 1999; Frevel et al. 2003). Other highly enriched ARE-cDNAs compared to the oligo-dT mini library are shown in Table 3, including the proinflammatory cytokines such as TNF- $\alpha$ and IL-1 $\beta$. All of the abundant AREmRNAs were either absent or less abundant in the oligo-dT mini library. An exception was the DSCR1, which apparently did not harbor an ARE in the RefSeq records of NM_004414. Two possible explanations: (1) This is a false positive, that is, a non-ARE mRNA, which in this case may indicate that, despite the low complexity of AREs, the described approach superiorly resulted only in a low false positive rate; (2) there is an alternative ARE-mRNA form. Our analysis of ESTs shows that there are both ARE and non-ARE alternative mRNA forms that can be transcribed from the same gene (K.S.A. Khabar, T. Bakheet, and B.R.G. Williams, in prep.). Nevertheless, we were able to clone ap- proximately 200 ARE-cDNA fragments that were not present in the oligo-dT library (Table 3). Many of those are chemokines, nucleic-acid-binding and transcriptional factors, and energy metabolism mediators. Table 3 lists those ARE-cDNAs that were mostly unique and abundant $(>0.3 \%)$ in the ARE-cDNA library. Many of these genes were previously shown to be upregulated in monocytic cells in response to lipopolysaccharide (LPS) in a large-scale microarray and SAGE expression profiling (Suzuki et al. 2000; Frevel et al. 2003).

Furthermore, we analyzed the ARE sequence patterns in the ARE-cDNAs by examining the computationally extracted 3' UTRs for Class I and Class II AREs. We found that our method was able to enrich for both Class I and Class II ARE-mRNAs (Table 3). Class I-ARE mRNAs represented $72 \%$ and Class II ARE-mRNAs represented 28\% in the ARE-cDNAs that were enriched in the ARE-cDNA library. Assessment of the human ARE-transcriptome (Bakheet et al. 2001, 2003) indicted that there are approximately $70 \%$ Class I ARE-mRNAs and 30\% class II AREmRNAs. Thus, these data support the potential use of the method on both Class I and Class II AREs without further adaptation.

A large proportion (almost a third) of ARE-cDNA fragments did not have significant matches (at minimum identity of $95 \%$ and minimum overlapping of $60 \%$ ) to mRNA records in GenBank, indicating that our approach may have led to the uncovering of novel hidden genes or alternative transcripts. Few of the known ARE-cDNA sequences such as interluekin- $1 \beta$ and the small inducible cytokine A4 were previously uncovered by our work on the ARE-cDNA PCR method (Khabar et al. 2002).

In conclusion, selection of ARE-cDNA can be achieved through use of one degenerate RT primer specific for AREs
TABLE 2. General and abundance characteristics of the ARE-cDNA and control libraries

\begin{tabular}{|c|c|c|}
\hline & $\begin{array}{l}\text { ARE-cDNA } \\
\text { mini-library }\end{array}$ & $\begin{array}{c}\text { OligodT } \\
\text { mini-library }\end{array}$ \\
\hline & $n=400$ & $n=176$ \\
\hline$\%$ of cDNAs with significant homology to HGP & $96 \%$ & $97 \%$ \\
\hline$\%$ of cDNAs with significant homology to ESTs & $67 \%$ & $89 \%$ \\
\hline$\%$ of cDNAs with no significant homology to mRNAs & $29 \%$ & $18 \%$ \\
\hline$\%$ of cDNAs with no significant homology to mRNAs or ESTs & $27 \%$ & $4 \%$ \\
\hline$\%$ of cDNAs with housekeeping ribosomal proteins & $4 \%$ & $29 \%$ \\
\hline$\%$ of cDNAs with known ARE-mRNA homology & $47 \%$ & $27 \%$ \\
\hline
\end{tabular}

Mini-libraries were generated from ARE-cDNA as described in text and in Materials and Methods or from oligo-dT primed cDNA (control). Colonies were randomly picked up and sequenced. A total of $\sim 600$ successful clones were generated. Abundance in percentages = number of sequences repeated for each gene/the total number of sequences, $n$. Identities of cDNA fragments were obtained by a filtered BLAST search against the human genome project (HGP), the human expressed sequence tag database (dbEST), and GenBank (cDNA/ mRNA molecules and Homo sapiens records only) as described in Materials and Methods. Presence of AREs was sought in computationally extracted 3' UTRs as explained in the Materials and Methods section. 
TABLE 3. Sequence and functional characteristics of ARE-cDNA library clones: A list of the most abundant and unique ARE-mRNAs

\begin{tabular}{|c|c|c|c|c|c|}
\hline Gene name & Accession no. & ARE library & Control library & ARE class & Function category \\
\hline Interleukin-8 & NM_000584 & $3 \%$ & $<0.5 \%$ & II & chemokine activity \\
\hline Tumor Necrosis Factor $\alpha$ & NM_000594 & $1 \%$ & $<0.5 \%$ & II & inflammation \\
\hline ATP synthase $\mathrm{H}+$ transporting subunit $\mathrm{g}$ & NM_0006476 & $1 \%$ & $<0.5 \%$ & 1 & energy metabolism \\
\hline Interleukin-1 $\beta$ & NM_000576 & $1 \%$ & $<0.5 \%$ & II & inflammation \\
\hline Small inducible Cytokine A4 & NM_002984 & $1 \%$ & $<0.5 \%$ & I & chemokine activity \\
\hline NADH dehydrogenase 2 & NM_173709 & $1 \%$ & $0 \%$ & I & energy metabolism \\
\hline Similar to cytokine (LOC339217) & XM_29076 & $1 \%$ & $0 \%$ & II & unknown \\
\hline Down syndrome critical region gene 1 & NM_004414 & $1 \%$ & $0 \%$ & 0 & transcriptional activity \\
\hline Early growth response 3 (LOC340061) & NM_004430 & $1 \%$ & $0 \%$ & 1 & tanscriptional activity \\
\hline TNF- $\alpha$ induced protein 3 (TNFAIP3) & NM_006290 & $1 \%$ & $0 \%$ & II & DNA-binding activity \\
\hline Growth arrest \& DNA-damage-inducible 34 & NM_014330 & $0.7 \%$ & $0 \%$ & 1 & cell cycle arrest \\
\hline Hypothetical gene (LOC340061) & XM_291127 & $0.7 \%$ & $0 \%$ & 1 & unknown \\
\hline Hypothetical protein (LOC286402) & XM_208415 & $0.7 \%$ & $0 \%$ & I & unknown \\
\hline Similar to isoleucine-tRNA synthetase & ВС008318 & $0.7 \%$ & $0 \%$ & 1 & nucleic acid metabolism \\
\hline Phosphatase mRNA & AF331843 & $0.7 \%$ & $0 \%$ & I & phosphatase activity \\
\hline Human cytokine (GRO- $\beta ;$ MIP- $2 \alpha)$ & NM_00289 & $0.7 \%$ & $0 \%$ & II & chemokine activity \\
\hline ATP synthase 8 (MTATP8) & NM_173703 & $0.7 \%$ & $0 \%$ & 1 & energy metabolism \\
\hline Zinc finger protein 313 & NM_018683 & $0.7 \%$ & $0 \%$ & II & DNA-binding activity \\
\hline Carboxypeptidase D (CPD) & NM_001304 & $0.7 \%$ & $0 \%$ & 1 & proteolysis/peptidolysis \\
\hline Similar to tumor protein & BC022436 & $0.7 \%$ & $0 \%$ & I & unknown \\
\hline NADH dehydrogenase 6 & NM_173714 & $0.7 \%$ & $0 \%$ & II & energy metabolism \\
\hline Putatative 28 kD protein, clone MGC:15140 & BC008304 & $0.3 \%$ & $0 \%$ & 1 & RNA binding \\
\hline cDNA DKFZp761M0223 & HSM802129 & $0.3 \%$ & $0 \%$ & 1 & protein kinase activity \\
\hline Dynein, cytoplasmic, light polypeptide 1 & NM_003746 & $0.3 \%$ & $0 \%$ & 1 & morphogenesis \\
\hline Integrin, $\beta 2$ & ВС005861 & $0.3 \%$ & $0 \%$ & II & cell adhesion \\
\hline cDNA FLJ14030 fis, clone & AK024092 & $0.3 \%$ & $0 \%$ & II & DNA-binding activity \\
\hline cDNA FJL00308 & AK122584 & $0.3 \%$ & $0 \%$ & II & unknown \\
\hline Chemokine $\mathrm{C}-\mathrm{C}$ motif ligand 4 (CCL4) & NM_002983 & $0.3 \%$ & $0 \%$ & I & chemokine activity \\
\hline Similar to small inducible cytokine A4 & ВC027961 & $0.3 \%$ & $0 \%$ & I & unknown function \\
\hline Nonkinase Cdc42 effector protein SPEC2 & BC050430 & $0.3 \%$ & $0 \%$ & I & signal transduction \\
\hline Ornithine decarboxylase antizyme 1 (OAZ1) & NM_00415 & $0.3 \%$ & $0 \%$ & I & nutrient metabolism \\
\hline RAS p21 protein activator 1 (RASA1) & NM_002890 & $0.3 \%$ & $0 \%$ & 1 & signal transduction \\
\hline cDNA IMAGE:4308472 & $\mathrm{BC} 007783$ & $0.3 \%$ & $0 \%$ & II & $\mathrm{C}-\mathrm{X}-\mathrm{C}$ domain \\
\hline Malate dehydrogenase & NM_005917 & $0.3 \%$ & $0 \%$ & II & energy metabolism \\
\hline Catenin, $\beta 1,88$ kD (CTNNB1) & NM_001904 & $0.3 \%$ & $0 \%$ & 1 & cell adhesion \\
\hline GRO- $\alpha$ (MGSA) & NM_001511 & $0.3 \%$ & $0 \%$ & II & chemokine activity \\
\hline Similar to nuclear receptor subf $1, \mathrm{~g} \mathrm{H}, 2$ & BC047750 & $0.3 \%$ & $0 \%$ & 1 & transcriptional activity \\
\hline cDNA FLJ11909 & AK021971 & $0.3 \%$ & $0 \%$ & I & unknown function \\
\hline Chemokine (C-C motif) ligand 3 & NM_002983 & $0.3 \%$ & $0 \%$ & II & chemokine activity \\
\hline Myelin oligodendrocyte glycoprotein & NM_002433 & $0.3 \%$ & $0 \%$ & II & neural development \\
\hline
\end{tabular}

in conjunction with optimized RT conditions. The AREspecific primer used for construction of the ARE-cDNA library allowed the detection of both Class I and Class II AREs. Other minute variations of primer design resulted in the same outcome of the enrichment of ARE-cDNA as measured by preferntial detection of IL- 8 cDNA over $\beta$-actin. However, the effect of the complexity on the ARE-cDNA library has not been evaluated with the different primers. Despite the low complexity of AREs, the described method resulted in significantly very few false positives (e.g., nonARE mRNAs). In addition to our previous PCR-based approach (Khabar et al. 2002) for selective amplification of ARE-cDNA, which was designed principally for differential display using multiple $5^{\prime}$ PCR primers, the ARE-cDNA method described here widens the applicability of the AREgene discovery and expression. The enriched cDNA can be used as a source for different applications including selection of cytokine and other ARE-cDNA for subsequent PCR applications, use with 5' RACE to clone full-length cDNAs, use with cDNA microarray and for discovery of low abundant ARE-mRNAs.

\section{MATERIALS AND METHODS}

\section{Cells and reagents}

The THP-1 monocytic cell line was obtained from the American Type Culture Collection (ATCC; Rockville, MD) and grown in RPMI 1640 supplemented with 10\% FBS (HyClone) and antibiotics (GIBCO BRL). The cells $\left(2 \times 10^{6} / \mathrm{mL}\right)$ in $15-\mathrm{mL}$ culture flasks were treated with $10 \mu \mathrm{g} / \mathrm{mL}$ of LPS (Sigma) and $5 \mu \mathrm{g} / \mathrm{mL}$ cycloheximide for $2.5 \mathrm{~h}$. 


\section{RNA and cDNA synthesis}

Total RNA was extracted from cells by the guanidine isothiocyanate method using Tri Reagent (Molecular Research Center). In many of the experiments, RNA was subject to DNAse I treatment followed by chloroform extraction, precipitation, and resuspension in diethyl pyrocarbonate (DEPC)-treated water.

The reverse transcriptase reaction was performed in a $20 \mu \mathrm{L}$ volume of a nuclease-free microcentrifuge tube. Total RNA ( 0.5 $\mu \mathrm{g}$ ) was heated first with ARE primers, AT-P or TA-P (Table 1), to $70^{\circ} \mathrm{C}$ for $10 \mathrm{~min}$ before quick chilling on ice. Contents were collected by brief centrifugation and the following were added: $1 \times$ First Strand Buffer (250 mM Tris-Cl at pH 8.3, $375 \mathrm{mM} \mathrm{KCl}, 15$ $\mathrm{mM} \mathrm{MgCl}$ ), $500 \mu \mathrm{M}$ dNTP mixture (GIBCO BRL), $10 \mu \mathrm{M}$ DTT (GIBCO BRL), and $20 \mathrm{U}$ RNAsin (Pharmacia). Contents of the tube were mixed gently and incubated at appropriate temperatures, depending on the RT used, and $200 \mathrm{U}$ of Moloney murine leukemia virus RT (GIBCO BRL) or SuperScript II (RNAse Hminus MMLV, GIBCO BRL) were finally added and the mixture further incubated for $2 \mathrm{~h}$. The reaction was inactivated by boiling. For conventional RT reactions, $500 \mathrm{ng}$ of anchored primers oligo $(\mathrm{dT})_{13} \mathrm{~A},(\mathrm{dT})_{13} \mathrm{C}$, and $(\mathrm{dT})_{13} \mathrm{G}$ primers were used instead of AT-P and TA-P primers (Table 1).

\section{Trehalose-mediated RT}

RT reaction utilizing trehalose was performed according to the Mizuno et al. (1999) method with modifications. Briefly, RNA and ARE primers were heated in a $30 \%$ glycerol solution at $65^{\circ} \mathrm{C}$ for 10 min, and cooled to $50^{\circ} \mathrm{C}$. The RT buffer mix, described above, was used but contained trehalose $(80 \% \mathrm{w} / \mathrm{v})$ and $0.1 \%$ BSA. The final concentration of trehalose in the RT reaction was approximately $20 \% \mathrm{w} / \mathrm{v}$. Superscript II was added at $200 \mathrm{U}$ per reaction, and the reactions were brought to an annealing temperature of $55^{\circ} \mathrm{C}-60^{\circ} \mathrm{C}$ for $2 \mathrm{~min}$ incubation. Finally, the reaction proceeded by further incubation for $1 \mathrm{~h}$ until inactivated by boiling.

\section{PCR}

Primers specific to the ARE-rich cDNA, IL-8, and the non-ARE rich cDNA, $\beta$-actin, were purchased from Clontech and Maxim Biotech, respectively (Table 1). Hot start PCR using 3.5 U Taq DNA polymerase (AmpliTaq) was performed in $50 \mu \mathrm{L}$ with $1 \mu \mathrm{g}$ of cDNA, dNTPs $(200 \mu \mathrm{M}$ each, final concentration $), 1 \times$ PCR buffer, and $0.4 \mu \mathrm{M}$ (final concentration) of primers. Amplification was performed at $94^{\circ} \mathrm{C}$ for $45 \mathrm{sec}, 60^{\circ} \mathrm{C}$ for $45 \mathrm{sec}$, and $72^{\circ} \mathrm{C}$ for $2 \mathrm{~min}$ (Gene Amp PCR System 9600; Perkin Elmer). The PCR was performed with conditions that allow semiquantitative assessment of IL- 8 and $\beta$-actin transcripts. These conditions were validated initially by performing multiple PCRs using different cycles and fixed template concentration. The cycle number for IL- 8 and $\beta$-actin was chosen, 33 and 24 cycles, respectively, so than the signal strength was within linearity. PCR products were resolved on $1.5 \%$ agarose gel and visualized with ethidium bromide. A 100-bp size marker ladder (GIBCO BRL) was used to verify the size of the IL-8 band (289 bp) and the $\beta$-actin band (642 bp). Primers were chosen to span exon and intron regions so that genomic contamination could be monitored by observing larger bands of $1320 \mathrm{bp}$ and 1216 bp belonging to IL- 8 and $\beta$-actin, respectively. In addition, each RNA sample was subject to testing by performing the PCRs with the mRNAs.

\section{Construction, sequencing, and bioinformatics of ARE-cDNA mini libraries}

The ARE-cDNA synthesized from total RNA using the above described ARE-cDNA synthesis approach or from oligo-dT-primer cDNA as a control was converted to double-stranded cDNA (ds cDNA) using second strand buffer (Gibco, Inc.) containing Escherichia coli DNA polymerase I (100 U) and RNAse $\mathrm{H}(4 \mathrm{U})$. The $\mathrm{ds}$ cDNA was extracted with phenol, ethanol washed, and resuspended in TE buffer, followed by blunt ending and phosphorylation in a single reaction using a T7blue2 blunt end cloning kit (Novagen). The ds cDNA was ligated into a pUC19 vector using the T7blue-2 Novagen kit; the ligated vectors were used to transform competent cells, and individual colonies, a total of approximately 600 clones, were randomly picked from large petri dishes. Colonies were propagated into 96-deep well blocks containing 1 $\mathrm{mL}$ volumes of LB medium containing ampicillin. The overnight cultures were directly used for amplification of the inserts in PCR buffer containing the following reactants: $1 \mathrm{U}$ Taq, $0.5 \mathrm{mM} \mathrm{M} 13$ primers, and $125 \mathrm{mM}$ dNTP with an initial denaturation step of $95^{\circ} \mathrm{C}$ for $1 \mathrm{~min}$, followed by constant 35 cycles of $94^{\circ} \mathrm{C}$ for $1 \mathrm{~min}$, $55^{\circ} \mathrm{C}$ for $1 \mathrm{~min}$, and $72^{\circ} \mathrm{C}$ for $1 \mathrm{~min}$.

Sequencing was performed with vector-specific primers flanking the inserts in the pUC19; PCR products were treated with $0.2 \mathrm{U}$ exonuclease I (New England Biolabs) and $0.2 \mathrm{U}$ sheep alkaline phosphatase in a $10 \mu \mathrm{L}$ final volume to degrade excess primers and dNTPs, respectively. These reactions were performed at $37^{\circ} \mathrm{C}$ for 1 $\mathrm{h}$ and terminated with heat $\left(85^{\circ} \mathrm{C}, 15 \mathrm{~min}\right)$. Templates were mixed with the sequencing DYEnamic ET reagent premix (Pharmacia), along with $10 \mathrm{pM}$ of the sequencing primers. Cycling was performed according to the manufacturer's instructions. Sequencing reactions were precipitated, washed, air dried, and resuspended in loading buffer. Parameters for injecting and running the samples were set according to the manufacturer's instructions (AmershamPharmacia).

The ARE-cDNA fragments' sequence data in a single FASTA file were the input for MEGABLAST to search human dbEST and GenBank nr database mRNA records (both RefSeq and nonannotated GenBank cDNAs) to retrieve the highest scoring record after the following criteria were met: $95 \%$ identity for mRNA records and $90 \%$ for EST records, word size of $32 \mathrm{bp}$, maximum Expect value of $<0.00001$, and limit by Entrez query of Homo sapiens [ORGANISM], biomol_mRNA[PROP]. As a control for vector and bacterial contaminant sequences, the sequences were also compared against the human genome using MEGABLAST.

Identities of matched mRNAs as ARE-mRNAs were obtained by searching the computationally extracted $3^{\prime}$ UTRs of the matching mRNAs with the minimum ARE motif, WWWT(ATT TA)TWWW, with mismatch -1 in either of the regions flanking the conserved pentamer as previously described (Bakheet et al. 2001, 2003). Because our previous ARED 2.0 was based on previous GenBank and RefSeq releases (2002), we used an update of ARED 2.0 based on the latest RefSeq release (April 2003). The 3' UTRs were also searched for Class I and Class II AREs (Chen and Shyu 1995). 


\section{ACKNOWLEDGMENTS}

The GenBank accession numbers for the sequence data are CD240066-CD240467.

The publication costs of this article were defrayed in part by payment of page charges. This article must therefore be hereby marked "advertisement" in accordance with 18 USC section 1734 solely to indicate this fact.

Received July 1, 2003; accepted December 19, 2003.

\section{REFERENCES}

Al-Humidan, A., Edwards, C.K., Al-Sofi, A., Dzimiri, M., Al-Sedairy, S.T., and Khabar, K.S.A. 1998. A carbocyclic nucleoside analogue is a TNF- $\alpha$ inhibitor with immunosuppressive action: Role of prostaglandin E2 and protein kinase $\mathrm{C}$ and comparison with pentoxifylline. Cell Immunol. 188: 12-18.

Bakheet, T., Frevel, M., Williams, B.R.G., Greer, W., and Khabar, K.S.A. 2001. ARED: Human AU-rich element-containing mRNA database reveals an unexpectedly diverse functional reportiore of encoded proteins. Nucleic Acids Res. 29: 246-254.

Bakheet, T., Williams, B.R., and Khabar, K.S. 2003. ARED 2.0: An update for AU-rich element mRNA database. Nucleic Acids Res. 31: 421-423.

Chen, C.Y. and Shyu, A.B. 1995. AU-rich elements: Characterization and importance in mRNA degradation. Trends Biochem. Sci. 20: $465-470$.

Duggan, D.J., Bittner, M., Chen, Y., Meltzer, P., and Trent, J.M. 1999. Expression profiling using cDNA microarrays. Nat. Genet. 21: 10-14.

Frevel, M.A., Bakheet, T., Silva, A.M., Hissong, J.G., Khabar, K.S., and Williams, B.R. 2003. p38 Mitogen-activated protein kinase-dependent and -independent signaling of mRNA stability of AU-rich element-containing transcripts. Mol. Cell. Biol. 23: 425-436.
Khabar, K.S., Dhalla, M., Bakheet, T., Sy, C., and al-Haj, L. 2002. An integrated computational and laboratory approach for selective amplification of mRNAs containing the adenylate uridylate-rich element consensus sequence. Genome Res. 12: 985-995.

Mizuno, Y., Carninci, P., Okazaki, Y., Tateno, M., Kawai, J., Amanuma, H., Muramatsu, M., and Hayashizaki, Y. 1999. Increased specificity of reverse transcription priming by trehalose and oligoblockers allows high-efficiency window separation of mRNA display. Nucleic Acids Res. 27: 1345-1349.

Murayama, T., Ohara, Y., Obuchi, M., Khabar, K.S., Higashi, H., Mukaida, N., and Matsushima, K. 1997. Human cytomegalovirus induces interleukin- 8 production by a human monocytic cell line, THP-1, through acting concurrently on AP-1- and NF- $\mathrm{kB}$-binding sites of the interleukin-8 gene. J. Virol. 71: 5692-5695.

Reeves, R. and Magnuson, N.S. 1990. Mechanisms regulating transient expression of mammalian cytokine genes and cellular oncogenes. Prog. Nucleic Acid Res. Mol. Biol. 38: 241-282.

Shaw, G. and Kamen, R. 1986. A conserved AU sequence from the 3' untranslated region of GM-CSF mRNA mediates selective mRNA degradation. Cell 46: 659-667.

Suzuki, T., Hashimoto, S., Toyoda, N., Nagai, S., Yamazaki, N., Dong, H.Y., Sakai, J., Yamashita, T., Nukiwa, T., and Matsushima, K. 2000. Comprehensive gene expression profile of LPS-stimulated human monocytes by SAGE. Blood 96: 2584-2591.

Winzen, R., Kracht, M., Ritter, B., Wilhelm, A., Chen, C.-Y., Shyu, A.-B., Müller, M., Gaestel, M., Resch, K., and Holtmann, H. 1999. The p38 MAP kinase pathway signals for cytokine-induced mRNA stabilization via MAP kinase-activated protein kinase 2 and an AU-rich region-targeted mechanism. EMBO J. 18: 4969-4980.

Yamada, M., Izu, H., Nitta, T., Kurihara, K., and Sakurai, T. 1998. High-temperature, nonradioactive primer extension assay for determination of a transcription-initiation site. Biotechniques 25: 72 $74,76,78$.

Zubiaga, A.M., Belasco, J.G., and Greenberg, M.E. 1995. The nonamer UUAUUUAUU is the key AU-rich sequence motif that mediates mRNA degradation. Mol. Cell. Biol. 15: 2219-2230. 

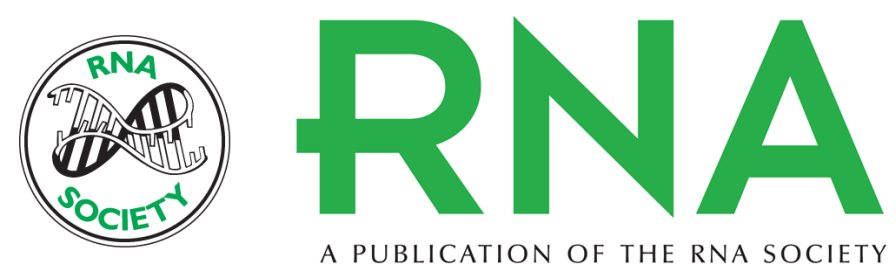

A PUBLICATION OF THE RNA SOCIETY

\section{Selection of AU-rich transiently expressed sequences: Reversal of cDNA abundance}

KHALID S.A. KHABAR, MOHAMMED DHALLA, LATIFA AL-HAJ, et al.

RNA 2004 10: 747-753

References This article cites 15 articles, 6 of which can be accessed free at: http://rnajournal.cshlp.org/content/10/4/747.full.html\#ref-list-1

License

Email Alerting Receive free email alerts when new articles cite this article - sign up in the box at the Service top right corner of the article or click here.

To subscribe to RNA go to:

http://rnajournal.cshlp.org/subscriptions 